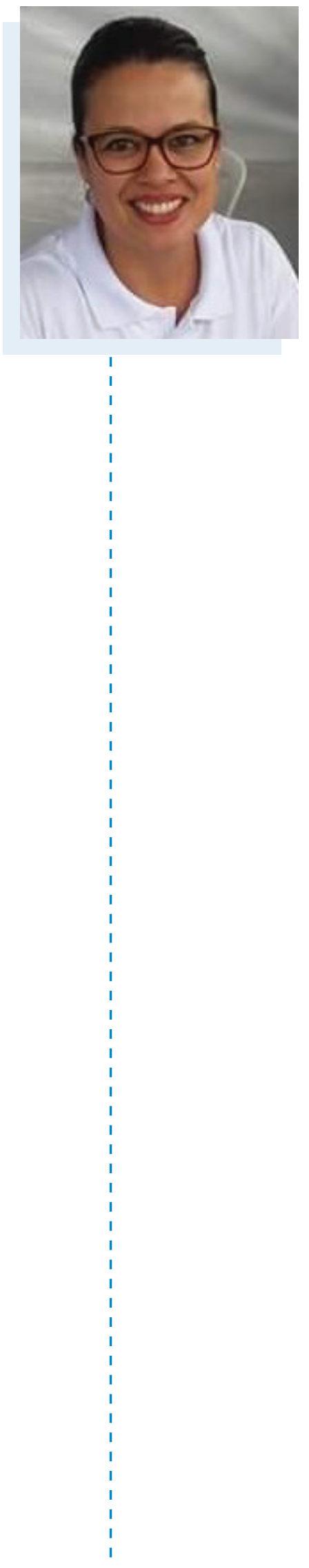

\title{
Nurses' performance in the area of incontinence: we can do more
}

Atuação do enfermeiro na área de incontinências: podemos fazer mais Actuación del enfermero en el área de incontinencias: podemos hacer más

\author{
Gisela Maria Assis
}

ORCID ID

Assis GM DiD https://orcid.org/0000-0001-6343-8075
HOW TO CITE

Assis GM. Nurses' performance in the area of incontinence: we can do more. ESTIMA, Braz. J. Enterostomal Ther., 17: e0719. https://doi. org/10.30886/estima.v17.761_IN

I would like to invite you to reflect on the work of our estimated stomatherapy, in the area of incontinence. Or, as I prefer to refer to it, the area of urinary and evacuation dysfunctions, understanding that dysfunctions go beyond urinary or fecal loss, also contemplating urinary retention and intestinal constipation.

Think for a moment which groups you belong today, study colleagues, work, family, childhood friends...how many people consist of your social networks? Try to ask in any of these groups if someone thinks they go to the toilet more often than other people if they have missed a few drops of urine by laughing or coming to the bathroom, if they have difficulty with evacuation or if their child urinates in the bed even having more than five years. Ask, too, what impact this has already caused in your life. You will be surprised by the answers. In all groups, there is someone who lives with these problems or who knows who lives them. Based on reviews, the International Continence Society reported that if we consider any type of urinary incontinence, the prevalence is $25-45 \%$ or at least two in 10 people live with involuntary loss of urine ${ }^{1}$.

Working in this area for more than 13 years, faced with the expressive demand of the Brazilian public health service, I dare say from experience that these people have not had the assistance they need and deserve. Initially, these people do not even seek the health service, either because they are not aware of what the symptoms represent or because they are ashamed to deal with it with a professional. When they come to seek professional help, they are frequently confronted with professionals who are also unaware of their help or who are embarking on surgical or medicinal approaches, with their risks and consequences, without 
this being the recommended approach as the first treatment, and there is so much to do in a conservative way, with such good results ${ }^{2}$.

When, on the one hand, I encounter the reality of the health system, on the other I realize how much we, nurses, can do for these people. We can act in prevention through the dissemination of simple measures that would prevent the manifestation of incontinence or its complications, acting early in the symptoms through guidance of simple behavioral measures (control of urinary interval, positioning for eliminations, water intake, muscle training of the pelvic floor), contribute to the recovery of autonomy and quality of life to women with pelvic organ prolapses by the insertion of vaginal pessaries or to the person with inferior urinary tract neurological dysfunction by the capacity for clean intermittent catheterization ${ }^{3}$.

The nurse's specialized actions prevent and treat urinary and evacuation dysfunctions effectively. The Federal Nursing Council, in its opinion 04/2016/TCHC/ FNC, supports us for this practice. I understand the nurse as the driving force of the health team, capable of changing the reality of incontinence in the Brazilian health system, without disregarding in any way the importance of the action of the other professionals involved in this area.

Although we are not many specialists in the country, I believe it is important to assume our social responsibility, both to provide specialized assistance and to enable generalist nurses to act in the many actions that are not exclusive to the stomatherapist nurse.

We, nurses, are everywhere and at all levels of health care; if we work in health education, we will be helping to avoid many cases of incontinence. If the early treatment comprises the nurse's action in basic care, we will reduce the queues to specialized hospitals and we will guarantee the secondary attention to more complex cases, optimizing the direction of resources.

Going beyond, we need to share our actions, our successes, and failures in the area. Research allows us to exchange, to learn from the mistakes and the correct answers of the other, to evolve in a group and as a category.

In this line of "we can do more" in front of this national scenario, I created, with two more stomatherapist nurses, the initiative called Flow, with the idea of joining forces to change this reality. We realized actions to raise public awareness about the prevention and treatment of urinary incontinence, through lectures, rounds of conversation, social media pages, and general media. We intend to contribute to the training of nurses to act in the attention to the person with urinary and evacuation dysfunctions, from basic care to specialized action. We intend to maintain a constant line of research in order to consolidate the nursing literature in the area.

The initiative we create is for the population, for the stomatherapy, for the nursing, for the health system; it is for you that you believe you can transform the reality where you live. Therefore, I invite you to continue with us in this process of change, to deepen knowledge about the nurse's role in this area, to put specialized knowledge at the service of the community, to systematize prevention and treatment actions in order to measure and share results, incontinence in programmatic contents of classes and lectures, research better approaches, finally, make the difference, incorporating the area in assistance, research, teaching, and extension.

\section{REFERENCES}

1. Abrams P, Cardozo L, Wagg A, Wein A. Incontinence. 6a ed. Tokyo: International Continence Society; 2017.

2. Brito F, Gentili R. Desatenção à mulher incontinente na atenção primária de saúde no SUS. Fisioter Bras. 2017;18(2):205-13.

3. Paterson J, Ostaszkiewicz J, Suyasa I, Skelly J, Bellefeuille L. Development and validation of the role profile of the nurse continence specialist: a project of the International Continence Society. J Wound Ostomy Continence Nurs. 2016;43(6):641-7. https://doi.org/10.1097/WON.0000000000000286 